\title{
Fuel-mediated Teratogenesis Use of D-Mannose to Modify Organogenesis in the Rat Embryo In Vivo
}

T. Buchanan, N. Freinkel, N. J. Lewis, B. E. Metzger, and S. Akazawa

Center for Endocrinology, Metabolism and Nutrition, and Departments of Medicine, Molecular Biology and Biochemistry, and Cell Biology and Anatomy, Northwestern University Medical School, Chicago, Illinois 60611

\begin{abstract}
The unique embryotoxic properties of D-mannose have been used as the basis for a new technique to secure precise temporal correlations between metabolic perturbations during organogenesis and subsequent dysmorphogenesis. Conscious, pregnant rats were infused with D-mannose or equimolar amounts of Dglucose by "square wave" delivery during the interval in which the neural plate is established and early fusion of neural folds takes place, that is, days 9.5-10.0 of gestation. Infusions of mannose to maternal plasma levels of $150-200 \mathrm{mg} / \mathrm{dl}$ did not elicit any toxicity in the mothers: motor activity, eating behavior, and serum components (electrolytes, osmolality, bilirubin) did not differ in glucose- vis-à-vis mannose-infused dams. Embryos were excised by hysterotomy on day $\mathbf{1 1 . 6}$ for evaluation of development. Examination with a dissecting microscope did not disclose developmental abnormalities in any of the $\mathbf{1 3 6}$ embryos from glucose-infused mothers or in 62 additional embryos from mothers that had not received any infusions. By contrast, dysmorphic changes were seen in 17 of 191 embryos (8.9\%) from mannose-infused mothers. 14 of the 17 had abnormal brain or neural tube development with incomplete neural tube closure in 9 instances. Abnormal axial rotation was present in 8 of the 191 embryos (4.2\%) and lesions of the heart or optic vesicles were seen in $4(2.1 \%)$ and $3(1.6 \%)$, respectively. Embryos from mannose-infused mothers displayed significant retardations in somite number, crown-rump length, and total protein and DNA content. These stigmata of growth retardation were more marked in the 17 dysmorphic embryos.

The experiments indicate that D-mannose may be employed in model systems with rodents for precisely timed interruptions of organogenesis in vivo. Initial applications are consistent with our earlier suggestion that multiple dysmorphic changes may supervene after interference with communally observed metabolic dependencies during organogenesis. The studies do not identify the vulnerable site(s) within the conceptus (e.g., investing membranes, embryos, or both). However, the findings suggest that dysmorphic events are manifest most markedly in a general setting of embryo growth retardation.
\end{abstract}

This work was presented in part at the Plenary Session of the 57th Annual Meeting of the Central Society for Clinical Research, Chicago, IL, 2 November 1984, and has been published as an abstract (1984. Clin. Res. 32:794, and 1984. J. Clin. Lab. Med. 104:652).

Address reprint requests to Dr. Buchanan, Center for Endocrinology, Metabolism and Nutrition, Northwestern University Medical School.

Received for publication 4 December 1984 and in revised form 8 February 1985.

J. Clin. Invest.

(C) The American Society for Clinical Investigation, Inc.

$0021-9738 / 85 / 06 / 1927 / 08 \quad \$ 1.00$

Volume 75, June 1985, 1927-1934

\section{Introduction}

Although congenital lesions are present in $3 \%$ of all births, the etiologic basis remains unexplained in $\sim 60 \%$ of cases (1). We have suggested that some dysmorphogenesis could be mediated via interference with fuel metabolism in the conceptus, especially during the periods of embryogenesis in which metabolic flexibility is limited $(2,3)$. As yet, this hypothesis has not been examined in vivo. Indeed, relatively few attempts have been made to correlate precisely timed exposures of offspring to an abnormal metabolic environment in utero with subsequent developmental abnormalities (4-11). In most of these, the period of metabolic disruption has been too long relative to the rapid development of the conceptus and/or too imprecisely documented to allow exact temporal assessments. Moreover, all previously employed perturbing agents have effected metabolic disturbances in the mother as well as in the conceptus, precluding differentiation between teratogenesis arising via direct effects in the offspring or as a secondary consequence of disturbed maternal metabolism.

Mannose may constitute an ideal tool for overcoming some of these problems. Its turnover in vivo appears to simulate that of glucose (12), so that brief and well-defined periods of exposure may be established. It also does not seem to have adverse effects in adult rats in vivo (13) or on isolated tissues from adult animals in vitro (14-21), whereas it has inordinate toxic actions in rat embryo culture $(2,3)$. In the latter, additions of $1.5 \mathrm{mg} / \mathrm{ml}$ mannose to incubation media containing $\sim 1.2 \mathrm{mg} / \mathrm{ml}$ glucose during culture from day 9.5 to 10.5 or from day 9.5 to 11.5 of development effects neural tube defects in about half of exposed embryos. To take advantage of these properties of mannose for the study of dysmorphogenesis in vivo, we have developed an equilibriuminfusion technique that allows delivery of rigidly controlled amounts of mannose during a finite phase of organogenesis. In the present initial effort with this approach, we have infused D-mannose in amounts designed to maintain plasma levels between 150 and $200 \mathrm{mg} / \mathrm{dl}$ in conscious, pregnant rats during the 12-h interval encompassing the establishment of the neural plate and the early fusion of the neural folds, that is, days 9.510.0 of embryonic development (22-25). At hysterotomy on day 11.6 of development, we found a significant incidence of dysmorphogenesis and growth retardation in the embryos. This experience has enabled us to secure the first well-documented temporal characterizations of the postulated causal interrelationships between altered intermediary metabolism in the conceptus and developmental anomalies. A preliminary account of these findings has been presented previously (26).

\section{Methods}

Animals. Virgin female rats of the Sprague-Dawley strain were obtained from Charles River Breeding Laboratories, Inc., Wilmington, MA. 
After at least $3 \mathrm{~d}$ of stabilization in an artificially lighted, controlled environment chamber (dark cycle: 1800-0500 hours) with free access to laboratory diet (Purina Rat Chow, Scientific Animal Feed, Chicago, IL) and tap water, females weighing $250 \pm 25 \mathrm{~g}$ were housed overnight with normal males of the same strain. Vaginal smears were examined for sperm at 0900 hours the following morning. Midnight of the night of mating was designated as day 0 of embryonic development; the subsequent 24-h period was considered the first day of gestation (27). Sperm-positive females were housed singly in cages with free access to water and laboratory diet except during infusions (see below). Animals and food were weighed daily between 0800 and 1000 hours to assess the effects of experimental procedures on body weight and food consumption.

Catheters for chronic blood sampling. Between 1600 and 1800 hours on the seventh day of gestation, that is, at day 6.7 of embryonic development, chronic indwelling venous catheters were inserted. Each animal was placed in supine position under ether anesthesia and a $1 / 2$ in. skin incision was made over the right jugular vein cephalad to the clavicle. A 5-in. segment of sterile polyethylene tubing (PE 50; Clay Adams, Div. of Becton, Dickinson \& Co., Parsippany, NJ) was inserted through a small nick in the ventral surface of the vein and the proximal tip was advanced to the junction of the vena cavae (28). The catheter was sutured in place, flushed with heparin solution (100 $\mathrm{U} / \mathrm{ml}$ in $0.9 \%$ saline) and the distal tip was plugged with a straight pin This tip was tunneled subcutaneously behind the right ear and externalized through a skin incision over the occiput. Animals were returned to the controlled environment chamber after incisions were closed. Catheter patency was subsequently maintained by twice-daily flushings with $0.1 \mathrm{ml}$ of heparin solution.

Catheters for acute infusions. At 0800 hours on the 10th day of gestation, that is, at day 9.3 of embryonic development, rats were returned to the laboratory and a 12 -in. segment of polyethylene tubing (PE 10; Clay Adams) was introduced percutaneously through a 20gauge needle into a lateral tail vein while each animal was briefly restrained in a towel. This catheter was advanced cephalad to the level of the caudal vein, flushed with $0.05 \mathrm{ml}$ of heparin solution, and its exposed portion affixed to the tail with adhesive tape. The distal portions of both tail and catheter were then drawn through a small hole in the side of the cage and secured there by placement of a onehole rubber stopper around the tail. This arrangement precluded access by animals to the unprotected portions of tail catheters while permitting them to remain conscious and move freely about during hexose infusions. Catheter patency was maintained by a continuous infusion of $0.9 \%$ saline $(0.1 \mathrm{ml} / \mathrm{h})$ until initiation of hexose infusions (see below).

Estimation of mannose "space" and turnover. To guide the development of a standard infusion protocol, attempts were made to quantify the turnover and virtual volume of distribution ("space") for mannose in the gravid rat. Derivations were secured according to the formulations of Newman et al. (29) as adapted for steady state conditions $(30,31)$ : distribution compartment ("space") = total clearance $/ k_{1}$. Total clearance of mannose from the mannose "space" (IVI) $P$ ) was calculated on the basis of the mannose concentration in the infusate $(I$; milligrams/milliliter $)$, the infusion rates $(V$; milliliters/ minute), and the plasma mannose concentrations at equilibrium $(P$, milligrams/milliliter) during 12-h mannose infusions. Plasma specimens were secured at 3-h intervals during infusions to document equilibrium and at four successive 10-min intervals after cessation of infusions to ascertain the fractional rates of mannose disappearance from the circulation $\left(k_{1}\right)$.

Hexose infusions. Animals were paired for concurrent equilibrium infusions of either D-mannose or D-glucose administered between days 9.5 and 10.0 of embryonic development. Infusions were initiated with a priming bolus of $0.54 \mathrm{mg} / \mathrm{g}$ body weight of the appropriate hexose delivered as a $30 \%$ solution in water $(\mathrm{wt} / \mathrm{vol})$ over $\sim 30 \mathrm{~s}$. This was followed immediately by a 12 -h sustaining infusion of the appropriate hexose, as a $5 \%$ solution in water (wt/vol), at the rate of $1.3 \mathrm{mg} / \mathrm{g}$ body weight per hour.

Infusions were delivered through tail catheters by a syringe infusion pump (model 355; Sage Instruments Div., Orion Research Inc., Cambridge, MA) and were designed to maintain plasma mannose levels between 150 and $200 \mathrm{mg} / \mathrm{dl}$, as based on the prior estimates of mannose distribution space and fractional turnover described above. Rats were given free access to water throughout the infusions. Heparinized blood samples were obtained from indwelling jugular catheters at $0,1,3,6,9$, and $12 \mathrm{~h}$; plasma was stored at $-20^{\circ} \mathrm{C}$ for subsequent analysis.

At the termination of hexose infusions, saline infusions were resumed. Animals were maintained with free access to food and water subsequent to hexose infusions.

Examination of embryos. Between 1600 and 1800 hours on the 12th day of gestation, that is, at day 11.6 of embryonic development, gravida were sacrificed by cervical dislocation. Uteri were excised rapidly, rinsed, and immersed at room temperature in $20 \mathrm{ml}$ of $0.9 \%$ saline contained within a petri dish $(100 \mathrm{~mm}$ Diam). Individual "embryo units" consisting of the embryo and associated membranes were freed of surrounding decidua and introduced into a second petri dish containing $20 \mathrm{ml}$ of saline. Embryos and investing membranes were teased apart with fine jewelers' forceps during visualization with a stereomicroscope (model M5A; Wild Heerbrugg Instruments, Inc., Farmingdale, NY). Embryos were then inspected for crown-rump length, somite number, and dysmorphogenic features according to a detailed checklist $(2,3)$. The efficacy of such inspection for detecting gross abnormalities at this stage of gestation has been amply documented (32).

After visual inspection, individual embryos were introduced into $0.5 \mathrm{~N} \mathrm{NaOH}$ for subsequent determination of total protein (33) and DNA $(34,35)$ content.

Materials and analytical methods. D-Mannose (Lot. No. 83F-0634; Sigma Chemical Co., St. Louis, MO) and D-glucose (Lot. No. KHMG; Mallinckrodt, Inc., Paris, KY) were prepared as solutions of 5\% and $30 \%(\mathrm{wt} / \mathrm{vol})$ in distilled water, sterilized by autoclaving and validated for hexose content by direct analysis before intravenous administration. Glucose (glucose analyzer II; Beckman Instruments, Inc., Palo Alto, CA) and mannose (36) concentrations were determined enzymatically; specimens were deproteinized with perchloric acid before mannose assay. Plasma immunoreactive insulin (IRI) ${ }^{1}$ was measured by doubleantibody radioimmunoassay using rat insulin standard (Novo Laboratories, Bagsvaard, Denmark). Plasma concentrations of creatinine, urea nitrogen, and electrolytes (ASTRA; Beckman Instruments, Inc., Brea, CA), and bilirubin (CentrifiChem System, Union Carbide Corp., Pleasantville, NY) were measured by automated techniques. Plasma osmolality was determined by freezing point depression ( $\mu$ Osmette; Precision Systems, Inc., Natick, MA).

Statistical analysis. All data are presented as group means \pm SEM. Intergroup differences in the prevalence of morphologic lesions were assessed by Fisher's exact test or $\chi^{2}$ analysis (37). All other comparisons were performed using unpaired or paired $t$ tests with corrections for multiple samples where appropriate (37).

\section{Results}

Mannose distribution and turnover in the gravid rat. Infusions of mannose from day 9.5 to 10.0 of gestation effected constant blood levels in gravid rats; disappearance of mannose from the circulation after the termination of infusions conformed to first-order kinetics. Analyses from three separate experiments disclosed clearance rates of $3.8 \pm 0.2 \mathrm{ml} / \mathrm{min}$ during infusions at mannose plasma levels of $184 \pm 4 \mathrm{mg} / \mathrm{dl}$ and postinfusion

1. Abbreviation used in this paper: IRI, immunoreactive insulin. 
disappearance rates of $0.04 \pm 0.001$ per $\mathrm{min}^{-1}$, corresponding to a mean half-time for mannose removal from the circulation of $17.5 \pm 0.35 \mathrm{~min}$. Derived values for the virtual volumes of mannose distribution in these three $10.0-\mathrm{d}$ pregnant rats averaged $32.3 \pm 0.8 \%$ of body weight. A representative experiment is depicted in Fig. 1. The above estimates formed the basis for the priming injections and infusion rates employed during subsequent standard infusion protocols.

Paired mannose and glucose infusions. 13 paired 12-h hexose infusions were carried out in 26 sperm-positive animals during days 9.5-10.0 of embryonic development. All mannose infusions were technically successful and all mannose-infused animals were found to be pregnant at hysterotomy on day 11.6, so that data from all 13 are included in the analyses that follow. Contrariwise, 2 of the 13 glucose-infused animals had to be excluded from analysis, one because jugular catheter occlusion precluded blood sampling during the glucose infusion and the other because there were no signs of pregnancy at hysterotomy on day 11.6 .

Concurrent values for plasma concentrations of glucose and mannose achieved during 12-h hexose infusions are depicted in Fig. 2. Plasma mannose concentrations were quantified only in the mannose-infused animals because plasma mannose has not exceeded $3 \%$ of concurrent glucose levels in nongravid or gravid rats in other experiments (Akazawa, S., and N. Freinkel, unpublished observations). Glucose infusions (Fig. 2, upper panel) elicited only slight and transient elevations of maternal glucose above preinfusion levels. Equimolar infusions of mannose (Fig. 2, lower panel) resulted in mean maternal plasma mannose levels that varied between $168 \pm 7$ and $188 \pm 5$ $\mathrm{mg} / \mathrm{dl}$ over the course of infusions, as was predicted from our preliminary kinetic studies. Concurrent plasma levels of glucose declined from $145 \pm 3 \mathrm{mg} / \mathrm{dl}$ preinfusion to $84 \pm 3 \mathrm{mg} / \mathrm{dl}$ during the first hour of mannose infusions, then fell more slowly to a nadir value of $64 \pm 3 \mathrm{mg} / \mathrm{dl}$ during the last $3 \mathrm{~h}$ of the $12-\mathrm{h}$ infusion period. Resultant mannose/glucose ratios varied from $2.1 \pm 0.1$ at $1 \mathrm{~h}$ to $2.9 \pm 0.1$ after $9 \mathrm{~h}$ of infusion.

These excursions in plasma hexoses were not attended by meaningful differences in plasma osmolality between mannose-

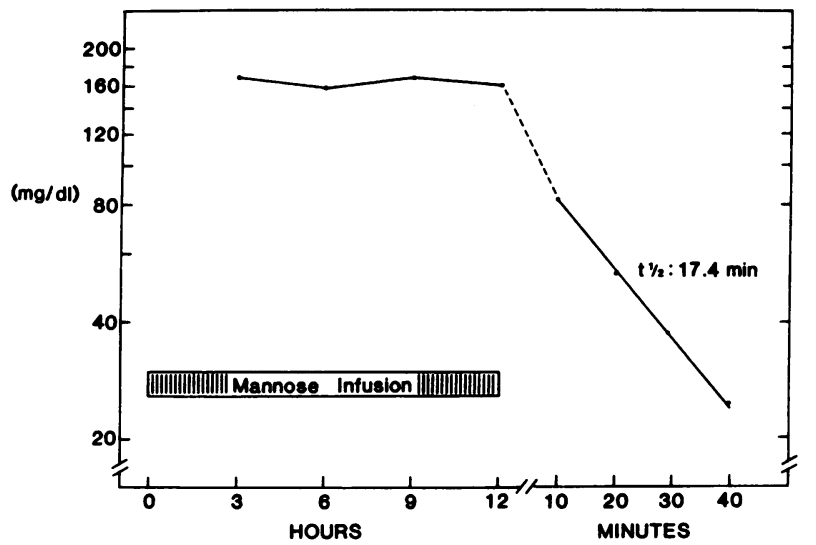

Figure 1. Plasma mannose concentrations (mg/dl) during and after a 12-h equilibrium infusion of mannose into a pregnant rat. The infusion was administered from day $9.5(0 \mathrm{~h})$ to day $10.0(12 \mathrm{~h})$ of embryo development and blood samples were secured as described in the text.

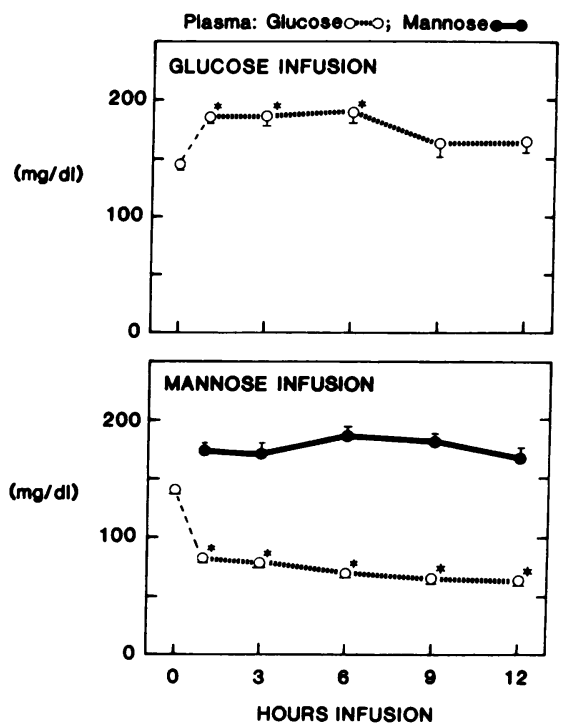

Figure 2. Plasma glucose and mannose concentrations during equilibrium infusions of glucose or mannose. Infusions were administered as described in Fig. 1. Significant changes in plasma glucose from preinfusion levels have been denoted as $*=P<0.001$.

and glucose-infused animals. Values measured at the end of the $12-\mathrm{h}$ infusions averaged $282 \pm 3 \mathrm{mosmol} / \mathrm{kg}$ and $284 \pm 3$ mosmol/ $/ \mathrm{kg}$, respectively.

Both mannose and glucose elicited significant increments in plasma IRI (Fig. 3). However, the magnitude and duration of these increments were significantly greater in glucose-infused animals. Thus, threefold increases above basal levels were achieved within $1 \mathrm{~h}$ in the glucose group and were maintained near that level throughout the subsequent $11 \mathrm{~h}$ of glucose infusion. Contrariwise, IRI rose to $\sim 50 \%$ above base line during the first hour of mannose infusions and declined to preinfusion levels thereafter, despite the persistently higher total hexose concentrations (i.e., mannose plus glucose) in that group (Fig. 2).

No apparent adverse effects were observed in mannosevis-à-vis glucose-infused mothers. Animals in both groups

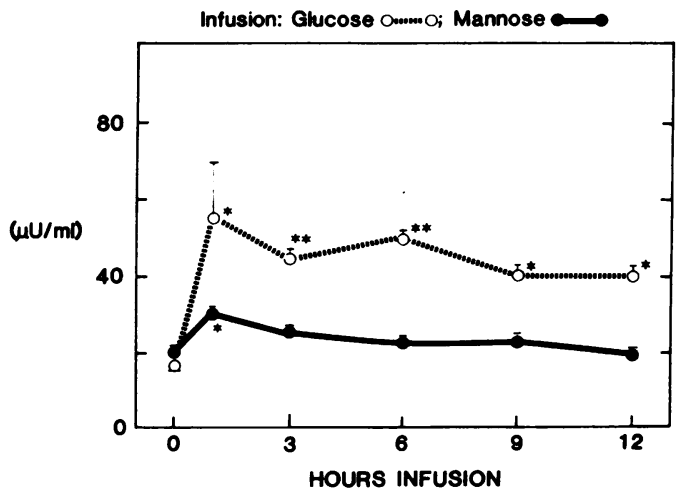

Figure 3. Plasma concentrations of IRI (microunits per milliliter) during equilibrium infusions of glucose or mannose. Infusions were administered as described in Fig. 1 . Significant changes in plasma IRI from preinfusion levels have been denoted as $*=P<0.01$ and ** $=P<0.001$. 
Table I. Effects of D-Mannose during Embryogenesis In Vivo: Frequency of Dysmorphogenesis*

\begin{tabular}{|c|c|c|c|c|c|c|c|}
\hline \multirow[b]{3}{*}{ Infusion } & \multirow{2}{*}{\multicolumn{2}{|c|}{ Embryos }} & \multicolumn{5}{|c|}{ Embryos with lesions of: } \\
\hline & & & \multirow[b]{2}{*}{ Brain } & \multirow{2}{*}{$\begin{array}{l}\text { Neural } \\
\text { tube }\end{array}$} & \multirow{2}{*}{$\begin{array}{l}\text { Axial } \\
\text { rotation }\end{array}$} & \multirow[b]{2}{*}{ Heart } & \multirow{2}{*}{$\begin{array}{l}\text { Optic } \\
\text { vesicle }\end{array}$} \\
\hline & Total & Dysmorphic & & & & & \\
\hline & $n$ & $n$ & $n$ & $n$ & $n$ & $n$ & $n$ \\
\hline Glucose & 136 & 0 & 0 & 0 & 0 & 0 & 0 \\
\hline Mannose & 191 & 17 & 13 & 9 & 8 & 4 & 3 \\
\hline
\end{tabular}

* Mothers were infused with equimolar amounts of D-glucose or Dmannose during days 9.5-10.0 of embryonic development as described in the text. Embryos were excised by hysterotomy on day 11.6 of development and examined for gross dysmorphogenesis. "Total (n)" denotes number of embryos in each group; "dysmorphic $(n)$ " denotes number with morphologic abnormalities; "embryos $(n)$ with lesions" refers to number with specific lesions and includes multiple listings for embryos with multiple abnormalities.

demonstrated apparently normal behavior during infusions including daytime sleep, increased activity during darkness, and appropriate arousal at times of blood sampling. Patterns of food intake and weight gain, as assessed by daily weighings of food and animals were likewise similar in the two groups both during and after the infusion interval. Comparisons of plasma samples which were pooled at the end of the hexose infusions (for microestimations) from three sets of mannose- infused and three sets of glucose-infused mothers disclosed no significant intergroup differences and uniformly normal values with regard to (mannose-infused vs. glucose-infused, respectively) sodium ( $137 \pm 2$ vs. $135 \pm 1 \mathrm{meq} /$ liter $)$, potassium $(4.1 \pm 0.1$ vs. $4.0 \pm 0.1 \mathrm{meq} / \mathrm{liter})$, urea nitrogen $(8.3 \pm 0.4$ vs. $7.9 \pm 0.4 \mathrm{mg} /$ dl), creatinine $(0.42 \pm 0.04$ vs. $0.50 \pm 0 \mathrm{mg} / \mathrm{dl})$, and calcium $(9.8 \pm 0.1$ vs. $9.6 \pm 0.1 \mathrm{mg} / \mathrm{dl})$. Serum bilirubin levels did not increase over the course of mannose infusions $(0.1 \pm 0 \mathrm{mg} / \mathrm{dl}$ preinfusion vs. $0.1 \pm 0.05 \mathrm{mg} / \mathrm{dl}$ after $12 \mathrm{~h}$ of infusion).

Embryo analysis. Hysterotomy on day 11.6 of gestation provided 136 embryos from 11 glucose-infused mothers and 191 embryos from 13 mannose-infused mothers. The frequency of absorbed conceptuses ( $6.2 \%$ for glucose vs. $6.8 \%$ for mannose) did not differ between these groups.

Detailed gross inspection did not disclose morphologic abnormalities in any of the embryos from the glucose-infused mothers (Table I). All had completely closed neural tubes; normal brain, heart and facial development; well-formed otic and optic vessicles; and completed axial rotation with a ventrally concave C-shaped curvature (Fig. 4, far left embryo). By contrast, 17 or $8.9 \%$ of the 191 embryos from 8 of the 13 mannose-infused dams had morphologic abnormalities in one or more organ systems (Table I). Embryos with dysmorphogenesis were distributed in all parts of the uterine horns.

Abnormalities of brain or neural tube development were present in 14 of the 17 dysmorphic embryos (i.e., $7.3 \%$ of the 191 embryos). Incomplete neural tube closure was present in

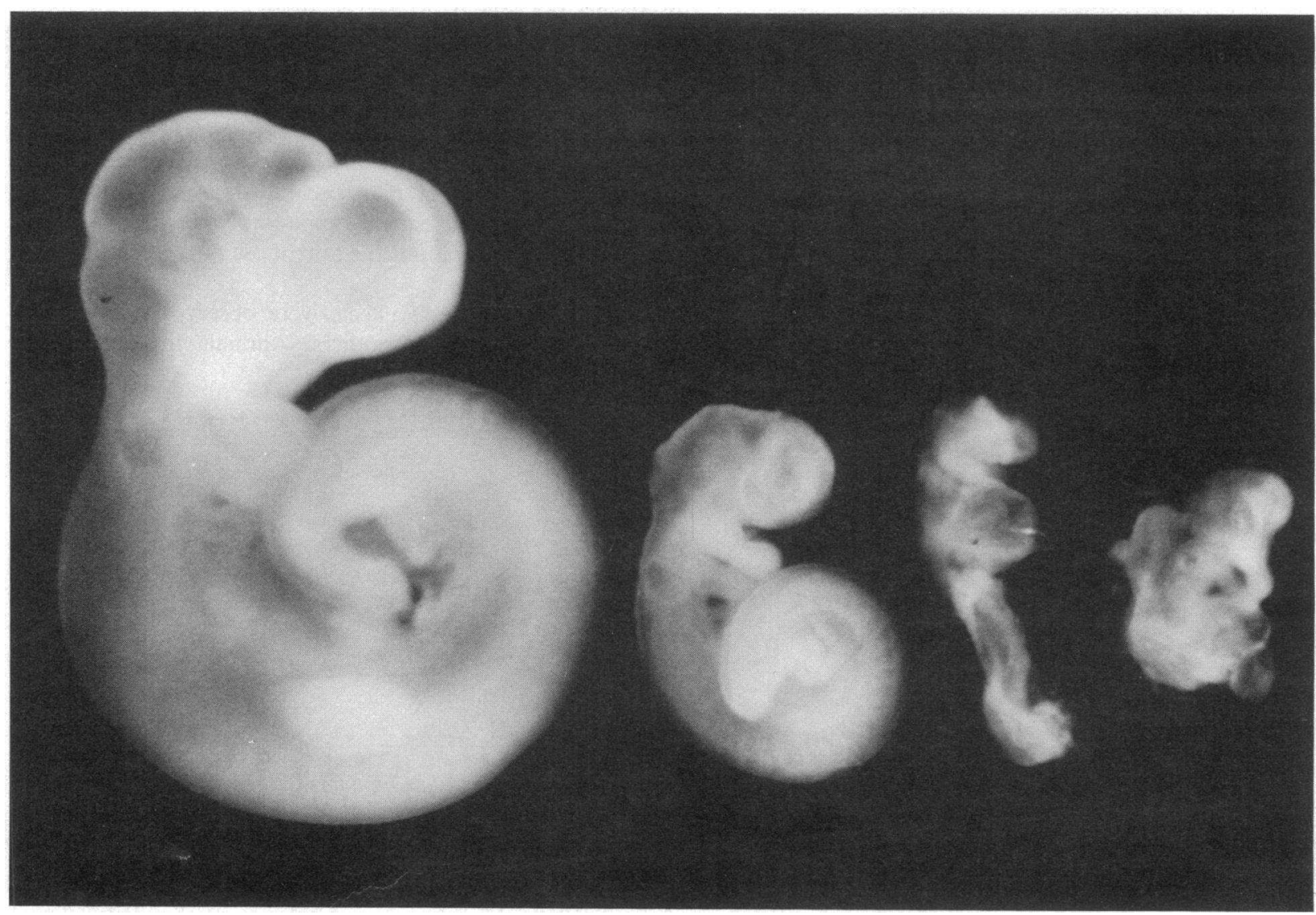

Figure 4. Dysmorphogenic effects of D-mannose in vivo. Embryos were removed on day 11.6 of development from mothers that had received 12-h equilibrium infusions of glucose (embryo on the left) or mannose (three embryos on the right) during days 9.5-10.0 as described in Fig. 1. Mannose-related lesions are described in the text. 
nine instances $(4.7 \%)$ and involved the entire neural tube in two cases, the midportion of the rhombencephalon in three others, and only the posterior neuropore in four embryos. 13 embryos (i.e., $6.8 \%$ of the 191 embryos) exhibited anomalous brain sphere development consisting of microencephaly ( $n$ $=8$; Fig. 4, second embryo from left) and/or a type of bloodfilled outpocketing of the ventrolateral walls of the prosencephalon ("bleb-formation"; $n=6$ ) analogous to what we have observed during embryo culture with mannose in vitro $(2,3)$. Faulty neural tube closure was present in 8 of these 13 embryos.

Abnormalities of axial rotation were observed in eight embryos (4.2\%) and ranged from failure to complete ventral flexion of the tail in seven embryos (Fig. 4, third embryo from the left) to complete dorsiflexion with "squirrellike" (38) fusion of the anterior to the posterior neural folds in one case (Fig. 4, far right embryo). Incomplete neural tube closure was present in five of these eight embryos.

Cardiac lesions consisting of S-shaped cardiac primordia were discernible in four $(2.1 \%)$ of the mannose-exposed embryos and abnormal development of the optic vessicles was present in three $(1.6 \%)$. All of these had brain and/or neural tube defects as well.

In addition to these gross disruptions of organogenesis, mannose infusion during days 9.5-10.0 of development resulted in a more generalized interference with embryo growth and differentiation. At examination on day 11.6, embryos from mannose-infused mothers displayed significantly lower mean values for somite number, crown-rump length, and total protein and DNA content than did embryos from the glucose group (Table II). Cell size, as èstimated by protein/DNA ratios, appeared to be unaffected by mannose. These findings were not confined to the embryos with gross dysmorphogenesis. Significantly reduced values for somite number, crown-rump length, and protein and DNA content were still present, although to a slightly lesser degree, when the 171 nonmalformed embryos from mannose-infused mothers were compared with the embryos from the glucose group (Table II). To assess whether these findings reflected a true interference by mannose with normal growth as opposed to a failure of the mannoseexposed embryos to match supranormal growth caused by glucose infusions, 62 embryos were excised on day 11.6 from five mothers that had received no infusions of any kind, but only continuing access to standard laboratory chow. Their values for somite number, crown-rump length, and protein and DNA content did not differ from those of the embryos from glucose-infused mothers $(P>0.05)$ and significantly exceeded the values in the embryos from mannose-infused mothers $(P<0.001)$ (Table II).

\section{Discussion}

In the present studies, we have attempted to use the relatively unique embryotoxic properties of D-mannose as part of a new approach for affixing precise temporal dimensions to the induction of dysmorphogenesis in vivo. Several technical problems had to be resolved to render such an approach feasible. An infusion technique had to be developed by which mannose could be delivered to gravid animals in early gestation without causing disruption of consciousness or activity patterns. Intravenous administration was particularly critical in view of the capricious absorption of mannose through the gastrointestinal tract (13). By using a combination of established techniques for chronic catheterization of the jugular (28) and tail (39) veins we were able to devise a dual catheter system for concurrently infusing gravid rats and sampling blood while they remained conscious and were able to move about. Presumably, this technique will prove to be equally useful for testing the effects of other agents upon embryonic development in vivo without seriously perturbing maternal activity. We additionally had to characterize mannose distribution and metabolic clearance in the pregnant rat so as to establish an expeditious protocol for achieving precisely timed and defined levels of mannose in maternal plasma by "square-wave" delivery. We obtained this information by an application of the principles of Newman et al. (29) and hope to apply these characterizations to future endeavors with different mannose challenges.

There are two assumptions intrinsic to the use of the present technique for the study of dysmorphogenesis in vivo. First, one has to assume that the relationship between mannose and glucose in the maternal circulation constitutes a valid reflection of the conditions that prevail within the conceptus. Although we have no direct proof that this is the case, the

Table II. Somite Number, Crown-Rump Length, Total Protein, Total DNA, and Protein/DNA Ratios of 11.6-d Rat Embryos from Uninfused, Glucose-infused, and Mannose-infused Mothers*

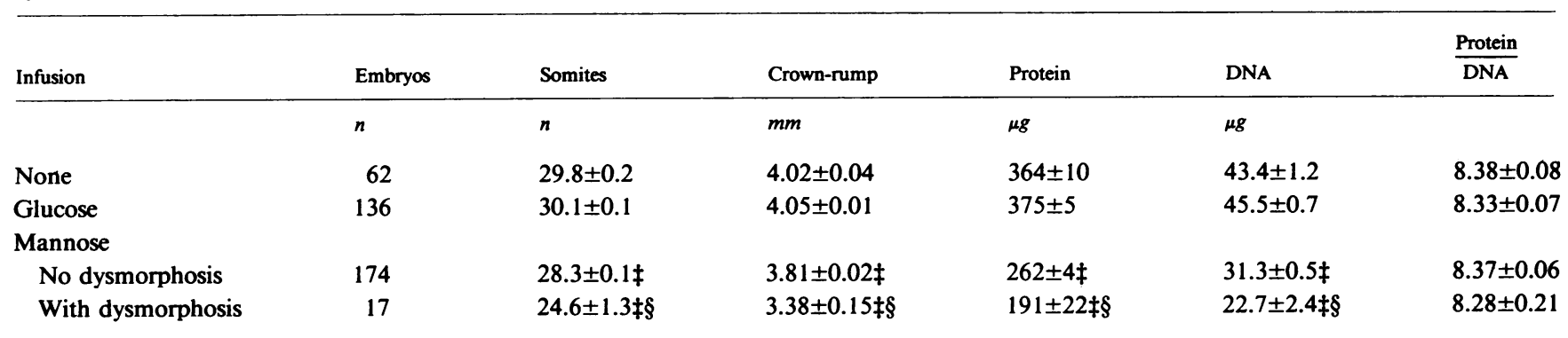

* Mothers were infused with D-glucose or D-mannose and embryos subsequently excised as described on Table I. "None" refers to additional control group of embryos in which mothers had received no infusions of any kind during days $9.5-10$ of embryonic development. Offspring from mannose-infused mothers $(n=191)$ have been subdivided into embryos without any gross evidence of dysmorphogenesis ("no dysmorphosis") and embryos "with dysmorphosis." Significance of differences between groups have been denoted as the following: $¥=P<0.001$ vs. embryos from uninfused or glucose-infused mothers; and $\S=P<0.001$ vs. embryos with "no dysmorphosis" from mannose-infused mothers. 
premise is not ill-founded. We administered hexose infusions during the day 9.5-10.0 period of embryonic development, before the establishment of the allantoic placenta and the full development of the yolk-sac circulation (40). During this interval, maternal plasma has direct access to the conceptus at the level of the visceral yolk sac (41). This situation is analogous to the conditions that prevail during rat embryo culture in vitro, where we have demonstrated that mannose and glucose are taken up by the conceptus in proportion to their relative concentrations in the culture medium $(2,3)$. Thus, maternal mannose and glucose concentrations should have accurately reflected the levels of these sugars directly available to the conceptus during infusions. The second assumption, that mannose toxicity is selective for the conceptus and not shared by the mother, is supported by substantial direct evidence. In confirmation of the findings of Wood and Cahill (13) in the nongravid adult rat (and contrary to their experiences with mannose administration in humans), we did not observe any elevation of serum bilirubin during mannose administration to rodent mothers. Maternal activity and feeding patterns were likewise not affected adversely. Moreover, mannose administration did not elicit abnormalities in other objective parameters, such as plasma electrolytes, urea nitrogen, creatinine, or osmolality. We did encounter a lowering of plasma glucose during mannose administration, as has been reported previously (13). The precise mediation remains uncertain and direct effects of mannose on the liver cannot be excluded. However, our finding that mannose infusions maintained plasma insulin at preinfusion levels despite concomitant decrements in plasma glucose suggests that mannose promoted insulin secretion by virtue of its well-documented insulin secretagogic potential $(42,43)$ and thereby may have restrained hepatic glucose output via a physiological rather than a toxic mechanism. In any event, neuroglycopenia and peripheral glucose deprivation can be excluded as significant complications, because infused mannose maintained the circulating hexoses (i.e., the sum of mannose plus glucose) above preinfusion levels and it has been shown that mannose, like glucose, can sustain energy metabolism in brain $(20,21)$ as well as in other tissues (14-19) of adult animals. It thus seems unlikely that the embryotoxicity of mannose in vivo was secondary to adverse effects of mannose on maternal functions which could delimit the effectiveness of the mother as an "incubator" (44) for the conceptus. Rather, the developmental defects that we have demonstrated in vivo may well constitute a replication of our experiences with mannose during culture of the intact conceptus in vitro $(2,3)$. However, and in keeping with our earlier caveat (3), we cannot differentiate between the effects of mannose on embryos, on their nurturing membranes (i.e., the visceral yolk sac), or on both of these, either in vivo or in vitro.

Within this framework, we found that sustained elevations of maternal plasma mannose to between 150 and $200 \mathrm{mg} / \mathrm{dl}$ (and mannose/glucose ratios to between 2 and 3:1) during the 12-h interval between days 9.5 and 10.0 of development resulted in grossly detectable morphologic defects in $8.9 \%$ of embryos subsequently examined on day 11.6. The abnormalities encountered were qualitatively similar to, although somewhat less frequent than those that we encountered after culture of rat conceptuses in vitro in the presence of similar mannose concentrations for longer intervals-i.e., 24 or $48 \mathrm{~h}$, from day 9.5 of development onward $(2,3)$. Conceivably, detailed histologic examinations might have disclosed additional abnormalities in both situations, but these were precluded by our desire to use the intact embryos for chemical characterizations. The $17.5 \mathrm{~min}$ half-life of mannose indicates that $>90 \%$ should have been cleared from the maternal circulation within $1 \mathrm{~h}$ after stopping infusions so that the total period for direct exposure to increased mannose in vivo could not have exceeded 13-14 h. Since it seems unlikely (although it remains to be proved) that intracellular increases in mannose metabolites such as mannose-6-phosphate would persist much beyond this interval, interference with programmed organogenesis by mannose should not have lasted beyond day 10.1 of development.

What steps of normal embryogenesis take place during this interval? With regard to neural tissue, the neural plate is established and neural folding begins; however, full closure of the anterior neuropore does not occur until day 10.7-10.8 and the posterior neuropore does not close until day 11.3-11.5, coincident with the completion of neural tube closure (2225). Clearly, therefore, the period of exposure to mannose coincided with the early phases of neural tube formation but preceded the periods for programmed anterior and posterior neuropore closure. Yet, at day 11.6 we encountered gross defects in neural development involving both of these structures. It is tempting to postulate that metabolic disruption within the conceptus between days 9.5 and 10.1 simply retarded the overall developmental sequence, displacing programmed events backward in time. The manifest reductions that we observed in the DNA and protein content of the embryos are consistent with this hypothesis. However, 13 of the 17 embryos exhibited lesions that never occur during the normal sequence of organogenesis, such as focal brain sphere defects, dysynchronous neural tube closure, and fusion of the anterior to the posterior neural folds. Development in these embryos must be considered to have been truly anomalous, suggesting that exposure to mannose during days 9.5-10.1 may have exerted some lasting effects on the anlage of neural tube structures. Thus, it seems more appropriate to hypothesize that the dysmorphogenesis may have been another and perhaps more extreme expression of the factors that produced the general retardation of embryo growth, and to extend thereby the suggestion (45-47) that birth defects occur more frequently in a setting of impaired embryo growth.

The above experiments still do not identify the primal process or processes that mannose compromises and from which such myriad changes would be derived. Earlier, we have suggested that mannose may act by interfering with glycolytic flux at a time when the conceptus has a limited capacity to generate energy by alternative metabolic pathways $(2,3)$. In this respect, mannose may serve as a prototype for the thesis that multiple, seemingly unrelated aspects of embryogenesis may be impaired when communally shared metabolic dependencies are compromised. Although other possible mechanisms of mannose action have been proposed by ourselves $(3,48)$ and others $(49,50)$, the present findings are still consistent with that proposition. Indeed, the temporal relationships that we have observed in the present studies would indicate that the putative actions upon "communally shared metabolic dependencies" may exert effects which extend beyond the actual period of exposure to mannose by affecting anlage within the nurturing membranes and/or embryo that underlie subsequent general cell replication as well as more specific steps in organogenesis and/or differentiation. However, none 
of these speculations explain why only 17 of 191 mannoseexposed embryos were dysmorphic; why dysmorphogenesis was present in the embryos of only 8 of the 13 mothers; and why some embryos from the same mother were spared while others were affected. Obviously, biologic factors other than "shared metabolic dependencies" must be operative and the examination of such fine nuances must await more targeted future studies by methods as yet to be defined.

\section{Acknowledgments}

The authors are indebted for the devoted technical assistance of Ms. Joyce Koren and for the excellent help of Mrs. Frances Novak, Ms. Concepcion Mora, and Mrs. Francesca Brutto in the preparation of this manuscript.

The study was supported in part by research grants AM-10699 and MRP HD-11021, and training grant AM-07169 from the National Institutes of Health

Dr. Buchanan was supported in part by a National Research Service Award from the National Institutes of Health (AM-07008) and by a Clinical Research Fellowship of the Chicago Community Trust. Dr. Akazawa was an Overseas Research Fellow (from Nagasaki University, Japan) at the Center for Endocrinology, Metabolism and Nutrition from 1981 to 1984 .

\section{References}

1. Kalter, H., and J. Warkany. 1983. Congenital malformations. Etiologic factors and their role in prevention. N. Engl. J. Med. 308: 424-431; 491-497.

2. Freinkel, N., N. J. Lewis, S. Akazawa, L. Gorman, and M. Potaczek. 1983. The honeybee syndrome: teratogenic effects of mannose during organogenesis in rat embryo culture. Trans. Assoc. Am. Physicians. 96:44-55.

3. Freinkel, N., N. J. Lewis, S. Akazawa, S. I. Roth, and L. Gorman. 1984. The honeybee syndrome-implications of the teratogenicity of mannose in rat-embryo culture. N. Engl. J. Med. 310:223230.

4. Smithberg, M., and M. N. Runner. 1963. Teratogenic effects of hypoglycemic treatments in inbred strains of mice. Am. J. Anat. 113: 479-489.

5. Takano, K., and H. Nishimura. 1967. Congenital malformations induced by alloxan diabetes in mice and rats. Anat. Rec. 158:303-312.

6. Hannah, R. S., and K. L. Moore. 1971. Effects of fasting and insulin on skeletal development in rats. Teratology. 4:135-140.

7. Spielmann, H., R. Meyer-Wendecker, and F. Spielmann. 1973. Influence of 2-deoxy-D-glucose and sodium fluoroacetate on respiratory metabolism of rat embryos during organogenesis. Teratology. 7:127134.

8. Deuchar, E. M. 1977. Embryonic malformations in rats, resulting from maternal diabetes: preliminary observations. J. Embryol. Exp. Morphol. 41:93-99.

9. Funaki, K., and K. Mikamo. 1983. Developmental-stage-dependent teratogenic effects of maternal spontaneous diabetes in the Chinese hamster. Diabetes. 32:637-643.

10. Baker, L., J. M. Egler, S. H. Klein, and A. S. Goldman. 1981. Meticulous control of diabetes during organogenesis prevents congenital lumbrosacral defects in rats. Diabetes. 30:955-959.

11. Eriksson, U. J., E. Dahlström, and C. Hellerström. 1983. Diabetes in pregnancy. Skeletal malformations in the offspring of diabetic rats after intermittent withdrawal of insulin in early gestation. Diabetes. 32:1141-1145.

12. Wyngaarden, J. B., S. Segal, and J. B. Foley. 1958. Physiological disposition and metabolic fate of infused pentoses in man. J. Clin. Invest. 36:1395-1407.

13. Wood, F. C., and G. F. Cahill, Jr. 1963. Mannose utilization in man. J. Clin. Invest. 42:1300-1312.
14. Folley, S. J., and T. H. French. 1949. The intermediary metabolism of the mammary gland. I. Respiration of lactating mammary gland slices in presence of carbohydrates. Biochem. J. 45:117-125.

15. Lutwak-Mann, C. 1949. Some aspects of bone marrow metabolism. Nature (Lond.). 164:607-608.

16. Abraham, S., and I. L. Chaikoff. 1959. Glycolytic pathways and lipogenesis in mammary glands of lactating and nonlactating normal rats. J. Biol. Chem. 234:2246-2253.

17. Ball, E. G., and O. Cooper. 1960. Studies on the metabolism of adipose tissue. III. The response to insulin by different types of adipose tissue and in the presence of various metabolites. J. Biol. Chem. 235:584-588.

18. Wool, I. G. 1960. Incorporation of $\mathrm{C}^{14}$ from $\mathrm{C}^{14}$-labeled sugars into $\mathrm{CO}_{2}$, nucleic acids and protein by isolated rat diaphragm. Am. J. Physiol. 198:649-651.

19. Wood, F. C., Jr., B. Leboeuf, A. E. Renold, and G. F. Cahill, Jr. 1961. Metabolism of mannose and glucose by adipose tissue and liver slices from normal and alloxan-diabetic rats. J. Biol. Chem. 236: 18-21.

20. Chain, E. B., S. P. R. Rose, I. Masi, and F. Pocchiari. 1969. Metabolism of hexoses in rat cerebral cortex slices. J. Neurochem. 16: 93-100.

21. Ghosh, A. K., B. Mukherji, and H. A. Sloviter. 1972. Metabolism of isolated rat brain perfused with glucose or mannose as substrate. $J$. Neurochem. 19:1279-1285.

22. Christie, G. A., 1962. Developmental stages in somite and postsomite rat embryos, based on external appearance and including some features of the macroscopic development of the oral cavity. J. Morphol. 114:263-286.

23. Witschi, E. 1962. Development: rat. In Biological Handbooks: Growth, Including Reproduction and Morphological Development. P. L. Altman and D. S. Dittmer, editors. Federation of the American Societies for Experimental Biology, Washington, D. C. 304-314.

24. Edwards, J. A. 1968. The external development of the rabbit and rat embryo. Adv. Teratol. 3:239-263.

25. Shepard, T. H. 1980. Catalog of Teratogenic Agents. Johns Hopkins University Press, Baltimore. Third ed. 1-529.

26. Buchanan, T., N. Freinkel, N. J. Lewis, B. E. Metzger, and S. Akazawa. 1984. Fuel-mediated teratogenesis: documentation of temporal relationships via a new technique. Clin. Res. 32:794a; and J. Clin. Lab. Med. 104:652.

27. Kalter, H. 1968. How should times during pregnancy be called in teratology? Teratology. 1:231-234.

28. Popovic, V., and P. Popovic. 1960. Permanent cannulation of aorta and vena cava in rats and ground squirrels. J. Appl. Physiol. 15: 727-728.

29. Newman, E. V., J. Bordley, III, and J. Winternitz. 1944. The interrelationships of glomerular filtration rate (mannitol clearance), extracellular fluid volume, surface area of the body, and plasma concentration of mannitol. A definition of extracellular fluid clearance determined by following plasma concentration after a single injection of mannitol. Bull. Johns Hopkins Hosp. 75:253-268.

30. Schwartz, I. L., D. Schachter, and N. Freinkel. 1949. The measurement of extracellular fluid in man by means of a constant infusion technique. J. Clin. Invest. 28:1117-1124.

31. Schwartz, I. L. 1950. Measurement of extracellular fluid by means of a constant infusion technique without collection of urine. Am. J. Physiol. 160:526-531.

32. Brown, N. A., and S. Fabro. 1981. Quantitation of rat embryonic development in vitro: a morphological scoring system. Teratology. 24: 65-78.

33. Lowry, O. H., N. J. Rosebrough, A. L. Farr, and R. J. Randall. 1951. Protein measurement with the Folin phenol reagent. J. Biol. Chem. 193:265-275.

34. Kissane, J. M., and E. Robbins. 1958. The fluorometric measurement of deoxyribonucleic acid in animal tissues with special reference to the central nervous system. J. Biol. Chem. 233:184-188. 
35. Hinegardner, R. T. 1971. An improved fluorometric assay for DNA. Anal. Biochem. 39:197-201.

36. Gawehn, K. 1974. D-mannose and D-mannose-6-phosphate. In Methods of Enzymatic Analysis. H. U. Bergmeyer, editor. Academic Press, New York. 1263-1267.

37. Snedecor, G. W., and W. G. Cochran. 1980. Statistical Methods. Iowa State Univ. Press, Ames, lowa. Seventh ed. 64-130.

38. Cockroft, D. L., and P. T. Coppola. 1977. Teratogenic effects of excess glucose on head-fold rat embryos in culture. Teratology. 16: 141-146.

39. Rhodes, M. L., and C. E. Patterson. 1979. Chronic intravenous infusion in the rat: a non-surgical approach. Lab. Anim. Sci. 29:8284.

40. Everett, J. W. 1935. Morphological and physiological studies of the placenta in the albino rat. J. Exp. Zool. 70:243-284.

41. Merker, H.-J., and H. Villegas. 1970. Elektronenmikroskopische untersuchungen zum problem des stoffaustausches zwischen mutter und keim bei rattenembryonen des tages 7-10. Z. Anat. EntwicklungsGesch. 131:325-346.

42. Lacy, P. E., D. A. Young, and C. J. Fink. 1968. Studies on insulin secretion in vitro from isolated islets of the rat pancreas. Endocrinology. 83:1155-1161.
43. Malaisse, W., F. Malaisse-Lagae, and M. Mahy. 1969. Effets du mannose sur la sécrétion d'insuline. Ann. Endocrinol. 30:595-597.

44. Freinkel, N., and B. E. Metzger. 1979. Pregnancy as a tissue culture experience: the critical implications of maternal metabolism for fetal development. In Pregnancy, Metabolism, Diabetes and the Fetus. CIBA Found. Symp. No. 63. Excerpta Medica, Amsterdam. 323 (discussion 23-29).

45. Pedersen, J. F., and L. Mølsted-Pedersen. 1981. Early fetal growth delay detected by ultrasound marks increased risk of congenital malformation in diabetic pregnancy. Br. Med. J. 283:269-271.

46. Spiers, P. S. 1982. Does growth retardation predispose the fetus to congenital malformation? Lancet. I:312-314.

47. Eriksson, U. J., N. J. Lewis, and N. Freinkel. 1984. Growth retardation during early organogenesis in embryos of experimentally diabetic rats. Diabetes. 33:281-284.

48. Freinkel, N., N. J. Lewis, S. Akazawa, S. I. Roth, and L. Gorman. 1984. Letter to the editor: Re: Honeybee syndrome, glycolysis and birth defects. N. Engl. J. Med. 310:1536.

49. Lazo, P. A. 1984. Letter to the editor: Re: Honeybee syndrome, glycolysis and birth defects. N. Engl. J. Med. 310:1535-1536.

50. Bucala, R., and A. Cerami. 1984. Letter to the editor: Re: Honeybee syndrome, glycolysis, and birth defects. N. Engl. J. Med. 310:1536. 